\title{
Analysis of common psychological problems of College Students
}

\author{
Zhang Yuanyuan \\ Dalian Vocational \& Technical College, Liaoning Dalian, 116035
}

Keywords: College student, Psychological problem, Solution

\begin{abstract}
As a special social group, college students are in a development of adapting themselves to social environment. Their psychology still in a transition period from immaturity to maturity. Because of their active mental activity, incomplete self-regulation ability, changes of learning environment, complex interpersonal relationships, employment pressure and so on. Some of college students don't adapt to this kind of life, even have mental disorder and mental disease. In recent years, it is often seen the phenomenon of dropping out from schools, self-destruction and crime. The mental health of college students is worrying. Therefore, it is necessary for college and universities to take cognizance of mental health of students and take measures to solve the problems.
\end{abstract}

\section{Introduction}

At present, it is a competitive society, as the main force of social development, college students are faced with various pressures. Psychological problems of modern College Students become more prominent, whether college students can adjust their psychology plays an important role. So mental health education project is very important for college students to be established in the highly competitive society

\section{Common Psychology Problem and Manifestation for College Students}

In the stage of becoming mature, the psychology of college students is not stable. Their psychology is more impressible and more intricate than the adult, so this lead to psychology problems, and summing up into following types.

Problems of Adjusting to College Life. Because of the changing of learning and living environment, college students is easy to tend conflict and confusion, and the data which is provided by investigation report shows that 30 percent freshers has varying degrees of adaptive problems. The main cause and manifestation are divided into four types. First, work-rest schedule and management style in universities are different from middle school. Second, the private space in dormitories is too narrow to live. Different personalities and life styles produce obstacle between roommates. Then, some of students have over dependence on their parents, so that they cannot fend for themselves. Finally, college students are far away from their relative ,familiar friends and teachers, so they are easy to create a lonely psychology and miss their hometown and their parents.Due to discomfort of life, college students may be insomniac anorexia, anxious and self-abased.

Problems of Academic. Learning is the main part of college life. The speed of learning progress, all the learning content and the level of grade may cause the changing of students' emotion and make psychological problems. There are five main reasons for psychological perplexity of college students on academic. First, facing the opportunities and challenges that brought by the changes of social development, college students recognize the importance of knowledge for the future life, in order to be the best one, some students are in the long-term tense leaning atmosphere. This lead to great pressure of study for college students. Second, some students choose subject that they don't like before they go to college, thus they lack enthusiasm of study. Third, after entering the university, students life changes a lot. Some of the students concentrate on study like high school. They play mobile phone and read novels in class. After class, they addicted to computer games and shopping. Then, some university freshmen were top students, but when they enter the college, their grades are 
not very ideal. They thought they review the knowledge carefully but the results are not good. This hit students' self-esteem and they lose their interests in study. Finally, when the exam is coming, students will become anxiety and fear in varying degrees, some students even suffer from text anxiety.

Interpersonal Relationship Problems. Interpersonal relationship is one of the three main problems in the psychological consultation in Colleges. Study of social psychology shows that a good interpersonal relationship is one of the most important factors to affect a person's mental development. Psychology of college students still in a stage of development. Their social experience is not rich and their emotionally is unstable, so the conflict often occurs. 80 percent of psychological problems of college students comes from poor interpersonal relationships. In the process of interpersonal communication, college students always have these following problems. The first is interpersonal loneliness. A large number of students will feel lonely when they enter the colleges. If students keep in such a state for a long time, it will increase the magnitude of the problem of interpersonal loneliness. The second is interpersonal conflict college students have a strong sense of self-respect. Some of them lack respects and comprehension during communication. They are too self centered, nitpick others even satire other people, and this results in communication barrier and cause pain for themselves. Third, college students don't know how to communicate with people. In college, schoolmates come from different cities or different nation. Thus there must have some divergence in ideological, value standard, customs and language culture, and there may be communication barriers.

Economic Burden. For some college students from countryside to city, they have a heavy economic burden. They have to pay for tuition and cost-of-living. In order to alleviate the pressure of life, some students look for a part-time job. The heavy economic burden make students have psychological pressure and inferiority.

The Psychological Problems of Sex and Love. College Students' sexual development is matured, love is inevitable. Students do not receive adequate education in puberty and lack the right guidance, a lot of students don't know what is true love, students cannot handle the relationship between the opposite sex correctly. Therefore, the psychological problems of sex and love become an important problem during the stage of development of college students.

For love, most of students can follow the norms of interpersonal communication. However, a small number of students show some mental problems in the process of love, for example, sometimes they cannot control their emotion and they are easy to be impetuous. The characteristics of college students' love are mainly as follow types: First, the freshmen start to find their lovers at the beginning of their college life. Second, university lovers don't shy away from others. They eat together and study together even kiss and embrace each other in public. Third, some students don't want to fall in love at the beginning. When their friends have boyfriends or girlfriends, they may fall in love with a person for snob value. Forth, some college students consider love as a love experience, they fall in love with more than one person and seek stimulation, they aren't responsible for affections. Finally, some students fall into misery and negative attitudes after lovelorn, even make light of their life.

For sexual psychological problems, some students step into youth, with the development of sex psychology, there may be some sexual psychological behaviors. For instance, they may be interested in sex knowledge and generate ideas of sex, even have masturbation behaviors. Some students lack sex knowledge, some students may fall into depression, this affects college students' study and life seriously.

Problems of Employment. University is the preparatory stage of society. At that time, the college students has formed their world view and outlook on life. They have the ability of analyzing and solving problems. They also have some changes on self-appraisal, self-supervision, self-command and self-realization, especially on independence and the development of moral consciousness. Therefore, they can deal with the problem rationally. They begin to think how to face to the choice of employment and how to spend the last time in the college. The problem of high grade students are mainly in the job. The employment status in current is both opportunities and challenges for college students. It provides a fair and equal competitive environment for every graduate. If college students 
do not have a positive attitude and a strong sense of competition, they wouldn't make a career or realize their dream. After the expansion of the scale of higher education, the number of college students keep raising. This leads to increased employment pressure. Then, by the influence of the bad atmosphere of society, some students are frustrated in job-hunting. They hate the bad phenomenon in society but feel helpless. At last, love, ideal and job conflict, they don't know how to choice, even some students are overwhelmed and have psychological problems.

The Problem of Internet Addiction. At present, the phenomenon of Internet addiction of college students is more common. Internet addiction includes the following types:

- Online game addiction. Some students spend a lot of time to on playing online games every day.

- Internet communication addiction. It is embodied in using chat room overmuch.

-Internet porn addiction. Some college students browse porn sites or participate in the network porn chat room.

-Compulsive information collection. This revealed in spending lots of time on collecting online information, but most of the information is useless.

- Network forcible behavior. Some students are forced to online gambling and online shopping.

\section{Solution to Psychological Problems}

Establish a Four - level Psychological Crisis Prevention and Intervention System. Establishing the university dormitory, class, faculty and school four psychological crisis prevention and intervention system. In dormitory, the leader of the dormitory and student cadre give full play to the role , caring for the roommates in variety ways. Once the abnormal situation is found, telling the class teacher and counselor immediately. In class, psychological commissioner understand the classmates' psychological dynamics though several ways. If they found someone has abnormal situation, reporting to counselor immediately. In faculty, appointing to psychological counselors, the establish archives of students' mental health. Counselors pay close attention to student behavior, talk to students and help students to solve the problems. In university, the school sets up psychological counseling centers and provide psychological counseling for the students who have psychological problems. Through the four psychological crisis prevention and intervention system can reflect psychological problems and intervene at once.

Popularize the Knowledge of Mental Health and Improve the Psychological Quality of College Students. Popularization of mental health knowledge is conducive to improving the psychological quality of college students. Schools should offer compulsory courses of mental health and carry out activities about mental health. The campus culture, which is combined with guiding education, is an important link of college students' mental health education. Healthy campus culture can help college students form the value of life. Through the activities, students can know about the knowledge of mental health problems.

Carry out Psychological Problems of Special Education. In the different periods of college students' growth, the main problem is different. So they need to be given different targeted counseling. On one hand, universities can divided psychological problems into several sections and educate students, such as interpersonal education, love and college should set up different courses for different grades because each grade has different psychological problems. For example, college should pay more attention to the counseling of adaptive psychological problems on grade-one students and help graduates build confidence.

Self-adjustment. When the psychological problem is not serious, self-adjustment can help students get out of the trouble. College students should have comprehensive understanding of themselves. They can improve self cognition by rethinking, talking to close friends and teachers, and doing psychological test. Through self-adjustment, students can transfer emotions and distract attention to stable mood. 


\section{Conclusion}

College students play a very important role in modern social life. As a special group, their psychology is especial, but they are not equal to the youth of society. From the situation of colleges, most students have healthy psychology, but there are also some students have mental problems, it is imperative to carry out the mental health education of college students and improve the management system of mental health education.

\section{References}

[1] Xu S P. Peer Psychological Counseling for College Students [M] Beijing: Science Press 2010-03-01

[2] Sun y h. course of College Students Psychological Health [M] Beijing: Beijing Institute of Technology press 2012-03-01

[3] yue j y. The influence of positive mental health education model on the psychological quality of Higher Vocational College Students. [J] Oriental Education.2015-12

[4] Peng R l. General psychology [M] Beijing: Beijing Normal University press 2004

[5] zhang x l. Report of professional and vocational college students 'psychological health status [j] Journal of Jilin Institute of Education 2015-7-31 